\title{
Anthropic Pollution Impacts on Groundwater Vulnerability Based on Modified DRASTIC-FAHP
}

Mohammad Reza Goodarzi ( $D$ Goodarzimr@yazd.ac.ir)

Yazd University https://orcid.org/0000-0002-6296-2315

Amirreza R. Niknam

Yazd University

Vahid Jamali

Yazd University

Hamid Reza Pourghasemi

Shiraz University School of Agriculture

Mahboobeh Kiani-Harchegani

Yazd University

\section{Research Article}

Keywords: Vulnerability, Groundwater, Modified DRASTIC, Fuzzy-AHP, Nitrate contamination, Iran

Posted Date: March 10th, 2021

DOI: https://doi.org/10.21203/rs.3.rs-245669/v1

License: (c) (1) This work is licensed under a Creative Commons Attribution 4.0 International License.

Read Full License 


\section{Anthropic pollution impacts on groundwater vulnerability based on modified DRASTIC-FAHP}

Mohammad Reza Goodarzi ${ }^{1, *}$, Amirreza R.Niknam ${ }^{2}$, Vahid Jamali ${ }^{2}$, Hamid RezaPourghasemi ${ }^{3}$, Mahboobeh 5

1) Assistant professor, Department of Civil Engineering, Yazd University, Yazd, Iran. Email:Goodarzimr@yazd.ac.ir

2) MSc student, Department of Civil Engineering, Water Resources Management Engineering, Yazd University, Yazd, Iran. E-mail:arshamrajabpour@gmail.com and couv.jamali@gmail.com

3) Associate professor, Department of Natural Resources and Environmental Engineering, College of Agriculture, Shiraz University, Shiraz, Iran. E-mail: hr.pourghasemi@ shirazu.ac.ir

4) Postdoc, Department of Watershed Management Engineering, Faculty of Natural Resources, Yazd University, Yazd Province, Iran. E-mail: mahboobeh.kiyani20@gmail.com

\section{Abstract}

In arid and semi-arid regions such as Iran, groundwater is more important for humans and ecosystems than surface water.Different models of groundwater vulnerability assessment can be used to better manage water resources. The purpose of this study is to evaluate the qualitative vulnerability of groundwater resources in the Birjand Plain aquifer using the DRASTIC model and 7 hydrogeological components. DRASTIC model was also modified by adding aland use component (MDRASTIC) based on Analytical Hierarchy Process (AHP) and Fuzzy Analytic Hierarchy Process (FAHP) methods. After calculating the vulnerability index, the vulnerability of each method was mappedand the final index obtained from each method was classified into 4 different categories. Nitrate concentrationwas used to confirm the results and to analyze the sensitivity of a single parameter. Sensitivity analysis showed that the groundwater vulnerability is mainly affected by water depth and land use.To validate each of the models, their correlation with nitrate concentration was calculated and compared. To determine the correlation coefficient, simple linear regression method was performed and the Pearson and Spearmanmethods were used. According to the obtained Pearson correlation results, the DRASTIC, MDRASTIC, MDRASTIC-AHP, and 
MDRASTIC-FAHP models resulted in values of 0.550, 0.680, 0.778, and 0.794respectively. The results show a good correlation between the modified DRASTIC-FAHP model and nitrate concentration as an indicator of groundwater pollution.

Keywords: Vulnerability, Groundwater, Modified DRASTIC, Fuzzy-AHP, Nitrate contamination, Iran

\section{Introduction}

All communities need a clean and plentiful source of water for drinking, health, agriculture, industry, and energy production (Maqsoom et al., 2020). In arid and semi-arid areas where surface water is less available, groundwater can be the main source of water supply due to its large volume and less vulnerabilityto pollution. Iran is a country where most of its area is made up of arid and semi-arid regions. Both qualitatively and quantitatively, water pollution problems have been worsening. Due to rapid and widespread increase in population, irregular planning, urban sprawl, different land use classification patterns and system, impropersewage disposal systems including sewage from industry, agriculture, and urban areas, water pollution problems have been alarming. (Singha et al., 2017; Kumar et al., 2018). Groundwater pollution treatment methods are very complex and it is also difficult to determine the level of pollution on a regional scale (Bai et al., 2012). Groundwater vulnerability assessment methods divide an area into different sub-areas in terms of susceptibility to pollution (Guo et al., 2006). Using this information, protective measures can be prioritized to the most vulnerable.Various models to assess aquifer vulnerabilities are available including DRASTIC (Aller and Robert, 1985), AVI (Stempvoort et al., 1993), SINTACS (Vrba et al., 1994), EPIK (Doerfliger and Zwahlen, 1997), and GODS (Foster et al., 2002). Of all the above models, DRASTIC, due to its simplicity and flexibility, has been used more than other models to assess groundwater pollution(Pacheco et al., 2015; Tiwari et al., 2016; Neshat and Pradhan, 2017). This model was developed by the United States Environmental Protection Agency (USEPA).Karami Shahmaleki et al. (2013) showed that the Analytical Hierarchy Process (AHP) method is more accurate than the combined logistic regression and modified DRASTIC methods for assessing aquifer vulnerability in the Dezful-Andimeshk. Shirazi et al. (2013) assessed the sensitivity to groundwater in Malacca state in Malaysia using GIS and DRASTIC methods and prepared a map to assess groundwater sensitivity based on land use. Mahmoudzadeh et al. (2013) studied the vulnerability of Isfahan-Meimeh Aquifer also in Iran using three methods including, DRASTIC, GODS, and AVI. The results of this study indicate the completeness of the DRASTIC methods for aquifer vulnerability. Sener and Sener (2015) used fuzzy-AHP DRASTIC to prepare a vulnerability map presenting DRASTIC characteristic coefficients calculated using FAHP and the value of the vulnerability index of the region. Sinha et al. (2016) Investigated the vulnerability of the Kharun Basin using a modified DRASTIC model. The final results showed a vulnerability index between 86 and 191. Also, using sensitivity analysis, water depth, land use, and topography parameters were selected as the most effective parameters. Hussain et al. (2017) evaluated a stressedaquifer in the Kut Do area in the Punjab Plain in India using DRASTIC model. This area is of environmental concern due to the increase of uncontrolled agriculture and source of non-point pollution and salinity. Jesiya and Gopinath (2019) 
71 DRASTIC factors were rated using FAHP and finally the information was integrated by GIS tool and areas with

72 high to very high vulnerabilities were identified. Maqsoom et al. (2020) studied the vulnerability of groundwater in

73 the Gilgit area of Baltistan in northern Pakistan. Due to urban sprawl, groundwater resources in this area are

74 declining. In this study, the GIS-based DRASTIC model was used and also because of the importance of human

75 activities in the DRASTIC model they combined the effects of the human factor as a parameter (DRASTIC-A).

76 Finally, comparison of the result with nitrate dispersion showed that the DRASTIC-A model has better results than

77 DRASTIC.

78 For this aim, four GIS-based methods including, DRASTIC, modified DRASTIC, AHP, and FAHP were applied to

79 map groundwater vulnerability in the research area. Also, for validation, the results obtained from four different methods were examined with nitrate concentration.

\section{Materials and methods}

\subsection{Study area}

The study area is Birjand Plain, which is located in the northern part of Bagheran highlands (latitudes $32^{\circ} 34^{\prime}$ to $33^{\circ}$ $8^{\prime} \mathrm{N}$ and longitudes $58^{\circ} 41^{\prime}$ to $59^{\circ} 44^{\prime} \mathrm{E}$ ) in Iran. The total area of Birjand Watershed is 3,425 square kilometers, of which about 980 square kilometers is composed of plain sand the rest is composed of mountains (Fig. 1). This plain is elongated and is surrounded by highlands and the central part consists of an alluvial aquifer (Eftekhari et al., 2019). It is bounded on the east by the Momenabad and Sistanhighlands, on the south by the Bagheran and Rech mountains, on the north by the Mol, Markuhhighlands, and on the west by the Karang and Chenghighlands. The Birjand plain is considered as an arid region according to climatic classifications. Annual rainfall is $177 \mathrm{~mm}$ and the altitude above sea level is 1,240 m (Aryafar et al., 2020).

Fig. 1.

\subsection{DRASTIC model}

97 DRASTIC is an acronym made up of the hydrogeologic parameters controlling groundwater pollution. These parameters include: depths to water (D), net recharge (R), aquifer media (A), soil media (S), topography (T), impact of vadose zone (I), and hydraulic conductivity (C) of aquifer. The DRASTIC model calculates a vulnerability index that is used to study groundwater pollution by hydrogeological parameters in different regions. The DRASTIC model results are calculated analytically and then processed using GIS. In the past few years, the DRASTIC model has been modified according to the characteristics of specificstudy areasby adding or removing various parameters (Lee, 2003; Wang et al., 2007; Simsek et al., 2006; Umar et al., 2009; Awawdeh and Jaradat, 2010; Martinez-Bastida et al., 2010; Şener and Şener, 2015; Jesiya and Gopinath, 2019; Maqsoom et al., 2020).The classification range for each parameter-between 1 and 10-indicates the impact of each parameter on aquifer vulnerability. Weights from 1 
ratings were generated by Aller and Robert (1985) using the Delphi method.The DRASTIC index is calculated using Eq. (1):

$D I=D r D w+R r R w+A r A w+S r S w+T r T w+I r I w+C r C w$

109

where, $r$ are the ratings allocated to each parameter and $w$ are the weights allocated to each parameter.

Higher DRASTIC index values indicate higher vulnerability and lower DRASTIC index values indicate lower region vulnerability.

Table 1

\subsubsection{Depth to water table}

Depth to water table is the depth that a pollutant must pass to reach groundwater so greater depth to water indicates less vulnerability. For areas with deeper water, more time is also available for pollution to decrease due to transformation or degradation of contaminants (Maqsoom et al., 2020). The classification of the depth to water table was 1 (minimum impact) to 10 (maximum impact) for input into DRASTIC.In general, deeper values correspond with lower DRASTIC rank values (Abdelmadjid and Omar, 2013; Natraj and Katyal, 2014; Ghosh et al., 2015; Tomer et al., 2019).To prepare this layer, data related to 18 piezometers, located in different places of the plain, were collected through the regional water of southern-Khorasan Province, in a one-year period from October 2017 to September 2018.ArcGIS 10.6 and interpolated using Kriging interpolation method in Spatial Analyst extension (Eftekhari et al., 2019; Tomer et al., 2019) (Fig. 2A).

\subsubsection{Net recharge}

Net recharge is the amount of water that infiltrates the surface and reaches the water table. This factor causes the vertical transfer of pollution to the water surface and its horizontal movement inside the aquifer (Maqsoom et al.,2020). The Piscopo method according to Equation 2 (Piscopo, 2001) was used to prepare the net recharge consisting of a total of three factors: slope, rainfall, and soil permeability. Rainfall maps were obtained using average annual rainfall data for years 2017 and 2018 prepared from theBirjand Meteorological Department.A slope map was obtained from Topographic map and digital elevation model, the detailed map resolution is 1:25000. Data and information related to soil permeability of Jihad Agricultural Office were also used to prepare the permeability map.Table 2 shows the classification and evaluation of net recharge and a net recharge map is shown in Fig. 2B.

Net recharge $=$ soil permeability + rainfall + slope $(\%)$

\section{Table 2}

\subsubsection{Aquifer media}

Aquifer media indicates the hydrogeology of the groundwater system and affects groundwater recharging, contaminant displacement, etc. (Remesan and Panda, 2008,Jesiya and Gopinath, 2019). To prepare the aquifer media zoning map, observation and operation well logs were used in the study area, obtained fromthe Regional 
water Department of southern Khorasan Province. Inverse Distance Weighting (IDW), in the ArcGIS Spatial Analyst extension, was used to prepare the aquifer map inthe ArcGIS 10.6 (Fig. 2C). This method was used because it has the lesserror than Kriging.

\subsubsection{Soil media}

Soil media refers toall the materials inthe upper part of the unsaturated area, dominated plants root infiltration and soil biological activities, which has a great impact on the rate of groundwater recharge (Baghapour et al., 2014; Noori et al., 2019). Soil properties such as permeability and soil texture can enablecontamination in the aquifer (Kim and Hamm, 1999). The soil map of the Birjandaquifer, scaled at 1:50000, was obtainedfrom the Jihad Agriculture Office of southern Khorasan. The map was scanned, digitized, rasterized and classified (Fig. 2D).

\subsubsection{Topography}

Topography refers to the slope of an area. Water is more likely to infiltrate in low-slope areas. In these areas, runoff amounts of runoff and are therefore lessvulnerable to groundwater pollution (Tomer et al., 2019). A slope map was prepared using DEM with a spatial resolution of 30 meters in ArcGIS 10.6 (Fig. 2E) (Eftekhari et al., 2019).

\subsubsection{Impact of vadose zone}

160

The impact of vadose zone on aquifer pollution is similar to soil media and depends on the permeability of the constituents and the characteristics of the unsaturated zone. To prepare this layer, logs of observation and operation of 22 wells obtained from the Regional Water Department of southern Khorasan Province, were interpolated using theIDW method in the ArcGIS 10.6 (Fig. 2F).

\subsubsection{Hydraulic conductivity}

Hydraulic conductivity refers to the ability of the aquifer to control the transfer of material. Aquifers with the highest hydraulic conductivity are most at risk of contamination (Tomer et al., 2019). To prepare this layer, Transmissivity data and information frompumping tests were obtainedfrom the Regional Water Department of southern Khorasan Province. Then, according to the Transmissivity parameter measured in experiment and dividing it by the saturation thickness of the aquifer, hydraulic conductivity is obtained (Pathak et al., 2009). Finally, hydraulic conductivity mapping was prepared using IDW method (Fig. 2G).

Fig. 2.

\subsection{Modified DRASTIC} map in this study, with a scale of 1: 50,000, was obtained from the Regional Water Department of South Khorasan 
and shrublands and river bed (Fig. 3) and were assigned DRASTIC ranks between 1 and 10. Incorporating land-use into DRASTIC resulted in a model referred to as MDRASTIC or DRASTIC-LU. The MDRASTIC index (MDI) was calculated using Eq. (3):

$M D I=D r D w+R r R w+S r S w+T r T w+I r I w+C r C w+L U r L U w$

where, $L U$ ris the rating of land use factor and $L U w$ is the weight of the land use factor.

Fig. 3

\subsection{Modified DRASTIC-AHP}

The Analytic Hierarchy Process (AHP) is a tool for efficiently analyzing complex decisions and thus helping the decision-maker choose the best possible option. This method was developed in 1980 by Thomas Saaty (Saaty, 1980) and applied in several fields. After calculating the weight of each parameter in the MDRASTIC method, the AHP tool was used to obtain new weights related to each parameter. Super decision software was used to prepare the weights of the parameters by AHP. Finally, for matrix compatibility, the consistency ratio (CR) value must be less than or equal to 0.1. If unsuccessful, the comparison answers should be re-examined (Sener and Davraz, 2012; Lakusic, 2019).

\subsection{Modified DRASTIC-FAHP}

The AHP method results in good results, but, it cannot reflect the style of human thinking (Kahraman et al., 2003). To make more reliable decisions, Van laarhoven and Pedrycz (1983) proposed the Fuzzy Analytic Hierarchy Process (FAHP). The FAHP method, determines the weight of the criteria primarily according to the subjective judgments of experts through a two-to-two comparison.In this method, comparisons are made using triangular numbers whose expansion indicates the uncertainty of a particular judgment(Şener and Şener, 2015). In fact, it gives more credibility and confidence to the judgments of experts (Şener and Şener, 2015). After Van laarhoven and Pedrycz (1983), Chang developed a new method for fuzzy AHP management in 1996 (Chang, 1996) using triangular fuzzy numbers (TFN)for a two-by-two comparison scale of fuzzy AHP and limit analysis method. Paired comparison numbers of one parameter compared to another can be seen in the fuzzy AHP method in Table 3 (Şener and Şener, 2015; Tseng et al., 2008). The numbers $2 / 3,1,3 / 2,2,5 / 2,3,7 / 2,4$, and $9 / 2$ were used as fuzzy scaling ratios, related to preferring one parameter over another with distance values.

Table 3

A fuzzy number may be expressed as a triangle or a trapezoid. In the triangular number (TFN), the corresponding number is expressed as $\mathrm{M}=(\mathrm{l}, \mathrm{m}, \mathrm{u})$. Parameter 1 represents the lowest possible value, $\mathrm{m}$ represents the most probable value and $\mathrm{u}$ represents the highest possible value for the desired number, and the desired number can vary 
between a and c(Şener and Şener, 2015). Kahraman et al. (2003) summarized the steps for calculating the relative weight of each criterion in the FAHP method proposed by Chang's extent analysis as follows:

216 Step 1: Formation of paired comparison matrix using fuzzy numbers

217 Step 2: Calculation of S matrix for each of the paired comparison matrix rows.

$S_{i}=\sum_{j=1}^{m} M_{g^{i}}^{j} \otimes\left[\sum_{i=1}^{n} \sum_{j=1}^{m} M_{g^{i}}^{j}\right]^{-1}$

218

219

220

$$
\begin{aligned}
& \sum_{j=1}^{m} M_{g^{i}}^{j}=\left(\sum_{j=1}^{m} l_{j}, \sum_{j=1}^{m} m_{j}, \sum_{j=1}^{m} u_{j}\right), \quad j=1,2, \ldots, m \\
& \sum_{i=1}^{n} \sum_{j=1}^{m} M_{g^{i}}^{j}=\left(\sum_{i=1}^{n} l_{i}, \sum_{i=1}^{n} m_{i}, \sum_{i=1}^{n} u_{i}\right), \quad i=1,2, \ldots, n \\
& {\left[\sum_{i=1}^{n} \sum_{j=1}^{m} M_{g^{i}}^{i}\right]=\left(\frac{1}{\sum_{i=1}^{n} u_{1}}, \frac{1}{\sum_{i=1}^{n} m_{1}}, \frac{1}{\sum_{i=1}^{n} l_{1}}\right)}
\end{aligned}
$$

Step 3: The degree of possibility of $M 2$ greater than equal to $M 1$ is defined as follows:

$V\left(M_{2} \geq M_{1}\right)=\sup _{y \geq x}\left[\min \left(\mu_{M 1}(x), \mu_{M 2}(y)\right)\right]$

$$
\begin{aligned}
& V\left(M_{2} \geq M_{1}\right)=h g t(M 1 \cap M 2)=\mu_{M 2}(d) \\
& =\left\{\begin{array}{cc}
1 \quad \text { if } m_{2} \geq m_{1} \\
0 \quad \text { if } l_{1} \geq u_{2} \\
\frac{l_{1}-u_{2}}{\left(m_{2}-u_{2}\right)-\left(m_{1}-l_{1}\right)} \quad \text { otherwise }
\end{array}\right.
\end{aligned}
$$


where, $\mathrm{M} 1=\left(\mathrm{l}_{1}, \mathrm{~m}_{1}, \mathrm{u}_{1}\right)$ and $\mathrm{M} 2=\left(\mathrm{l}_{2}, \mathrm{~m}_{2}, \mathrm{u}_{2}\right)$ are two triangular fuzzy numbers and $\mathrm{d}$ is the highest point of intersection between $\mu_{M 1}$ and $\mu_{M 2}$ (Fig.4). Step 4: In this step, the non-normalized weight vector was obtained by calculating the minimum value of V calculated in the previous step.

232

$\min V=\left(M \geq M_{i}\right), \quad i=1,2, \ldots, k$

$d^{\prime}\left(A_{i}\right)=\min V\left(S_{i} \geq S_{k}\right) \quad k=1,2, \ldots, n ; k \neq i$

$W^{\prime}=\left(d^{\prime}\left(A_{1}\right), d^{\prime}\left(A_{2}\right), \ldots, d^{\prime}\left(A_{n}\right)\right)^{T} A_{i}(i=1,2, \ldots, n)$

Step 5: The weight vector obtained from the previous step, which was not normalized, was normalized to obtain the final weight vector, which is our ultimate goal in the fuzzy calculations

$W=\left(d\left(A_{1}\right), d\left(A_{2}\right), \ldots, d\left(A_{n}\right)\right)^{T}$

\section{Fig. 4}

\subsection{Sensitivity analysis}

Because the DRASTIC model supports large-scale data sets, uncertainty should be considered in improperly assigning rating and weight at each stepto mitigate wrong final output and impacts onthe computational process of the DRASTIC model.Sensitivity analysis allows providing valuable information about the values of ratings and weights (Gogu and Dassargues, 2000; Edet 2014; Şener and Şener, 2015). In this study, the single-parameter sensitivity analysis (SPSA) was performed.

\subsection{Single parameter sensitivity analysis}

247 This analysis was introduced by Napolitano and Fabbri (1996), to evaluate the effect of each of the parameters of the MDRASTIC model in measuring vulnerability. The theoretical weight for each parameter was compared to the effective weight which is calculated using Eq. 14:

250

$$
W=\left[\frac{\left(P_{r} \times P_{w}\right)}{V}\right] \times 100
$$

252 where, $W$ is the effective weight of each parameter, $\operatorname{Pr}$ and $P w$ are the ratings and weight related to that parameter, 253 respectively, and $V$ is the total vulnerability index in that area. 


\subsection{Validation}

256 Simple linear regression analysis (SLRA) was used to comparethe results of the four DRASTIC methods to nitrate

257 concentration parameter to evaluate the correlation. Pearson, Spearman correlation coefficients (Panagopoulos et al.,2006;Kumar and Pramod Krishna, 2019; Maqsoom et al., 2020) were also used to evaluate the degree of correlation between models and nitrate concentration parameter to select the best method. Pearson's correlation coefficient $(r)$ determines the correlation between two variables with distance and relative scales, assuming a normal distributionand varies between +1 and -1 (Chok, 2010). It was calculated using Eq. 15:

262

$$
r=\frac{\sum_{i=1}^{n}\left(x_{i}-\bar{x}\right)\left(y_{i}-\bar{y}\right)}{\sqrt{\sum_{i=1}^{n}\left(x_{i}-\bar{x}\right)^{2}} \sqrt{\sum_{i=1}^{n}\left(y_{i}-\bar{y}\right)^{2}}}
$$

Where $r$ is the correlation coefficient, $x_{i}$ represents values of the $\mathrm{x}$-variable in a sample, $\overline{\bar{x}}$ represents mean of the values of the $\mathrm{x}$-variable, $y_{i}$ represents values of the y-variable in a sample and $\overline{\bar{y}}$ represents mean of the values of the y-variable. The Spearman's rank correlation coefficient is a nonparametric measure used to quantifythe strength of a link between two sets of data (Laerd Statistics, 2018; Kumar and Pramod Krishna, 2019).It was calculated using Eq. 16:

$$
\rho=1-\frac{\sum_{n-1}^{n} d^{2}}{n\left(n^{2}-1\right)}
$$

273 Where $\rho$ is the Spearman's rank correlation coefficient, $d$ represents difference between the two ranks of each 274 observation and $n$ represents number of observations. Nitrate data used were collected by 22 wells in the study area. 275 Excel was used for linear regression model (Abdullah et al., 2018) and SPSS 26 was used for Pearson, Spearman 276 correlations (Asgari Moghaddam et al., 2016; Baghapour et al., 2016).

\section{Results}

\subsection{DRASTIC}

281 After obtaining the ratings and weights of each parameter (Table 4), the final vulnerability map was created using ArcGIS 10.6.A quantile classification method was used to classify vulnerability categories in the final map.The set of values available by this classification method is divided into groups with equal numbers of values(Sener et al., 
2009).The results of this model showed that $5 \%$ of the aquifer has a low vulnerability class (79-95), $38 \%$ has a medium vulnerability (96-112) , 46\% has a high vulnerability (113-129) and 11\% has a very high vulnerability (131146) (Fig. 6(A)).

\subsection{Modified DRASTIC}

The MDRASTIC index was calculated using Eq. 3 and a vulnerability map was generated using ArcGIS 10.6. The resulting map was divided into four vulnerable areas using a quantile classification method that varied from low to very high. TheMDRASTIC model, incorporating land use as a parameter resulted in a different distribution of vulnerability indices the standard DRASTIC method.The results of the MDRASTIC model showed that $4 \%$ of the Birjand aquifer has a low vulnerability class (90-113),59\% has a medium vulnerability (114-137), 29\% has a high vulnerability (138-161) and 8\% has a very high vulnerability (162-185) (Fig. 6(B)).

\subsection{Modified DRASTIC-AHP}

The value of compatibility ratio (CR) was 0.023 , which indicates the correctness of the comparisons (Fig. 5). According to the new weights, layers of each parameter were created in the GIS environment, and finally, a vulnerability map was prepared. The results of the MDRASTIC-AHPmethod showed that $4 \%$ of the Birjand aquiferhas a low vulnerability class (3.4-4.1), 52\% has a medium vulnerability (4.2-4.9), 39\% has a high vulnerability (5-5.7) and 5\% has a very high vulnerability (5.8-6.5) (Fig.6(C)).

Table 4

Fig. 5

\subsection{Modified DRASTIC-FAHP}

MDRASTIC F-AHP vulnerability index was also obtained using the rating and weight determined for each parameter by the F-AHP method (Eq.4). The groundwater vulnerability map was also generated using the modified weights and ArcGIS 10.6 and it was divided into four vulnerable areas using a quantile classification method that varied from low to very high. The results of MDRASTIC-FAHP method showed that $2.8 \%$ of the aquifer area has a low vulnerability class $(0.09-0.162), 53.2 \%$ has a moderate vulnerability $(0.163-0.235), 40.3 \%$ has a high vulnerability (0.236-0.308) and 3.7\% has a very high vulnerability (0.309-0.381) (Fig.6(D)).

Fig. 6

\subsection{Single parametric sensitivity analysis}

Statistical results of SPSA were presented for the DRASTIC model. Comparison of the theoretical weight of each parameter with the effective weight assigned to it in the aquifer of the studied plain showed that the theoretical and effective weights of each of the parameters of the DRASTIC model are not completely consistent. According to Table 5, the depth to water table parameter with an average effective weight of 23.6 is the most sensitiveparameter in assessing vulnerability. The theoretical weight determined by the DRASTIC model is less than the average effective weight of this parameter. Also, land use, aquifer media, the impact of vadose zone and hydraulic 
conductivity have a more effective weight than the theoretical weight assigned to them in the DRASTIC model. It can also be seen from the sensitivity analysis that the net recharge and topography parameters have the least effect on groundwater vulnerability.

\subsection{Validation}

The relationship between nitrate concentration and vulnerability indices obtained from different DRASTIC methods was used to evaluate and select the best method, based on the assumption that the most vulnerable areas in the aquifer should also experience the highest nitrate concentrations.Using nitrate field data obtained from 22 wells in the Birjand aquifer, the vulnerability map was confirmed (Fig. 7). Human and agricultural activities result in elevated concentration of nitrate in groundwater.Fig. 8shows simple linear regression analysis diagrams to examine the correlation between the calculated indices and the values of groundwater nitrate concentration. The closer the $\mathrm{R}^{2}$ values are to 1, the greater the correlation of the method. Also, to confirm and select the best method, the resulting vulnerability maps were evaluated using Pearson and Spearman correlation methods in SPSS 26 (Table 6). The results presented in Table (6) show a higher correlation of the FAHP vulnerability map with the nitrate concentration.

\section{Discussion}

Assessing and preventing groundwater contamination is essential for better and more efficient management of these resources.In this regard, various methods such as DRASTIC can be used to integrate different thematic layers to evaluate groundwater vulnerability in the desired area. The DRASTIC model considers 7 hydrogeological parameters and classifies them on a ten-grade scale. Finally, the parameters are combinedin Eq1 to calculate a vulnerability index.The depth that a pollutant must travel to reach groundwater is called the depth to water table, or in fact, it can be said that the contaminant must travel after infiltrating the ground to reach the groundwater level.in this studydepth was divided into three intervals, namely, 9-15, 15-23, and > 30.4 meters.Factors that combine to parameterizenet rechargeinclude soil permeability, slope, and precipitation. (Piscopo, 2001).To prepare the net recharge map, aslope map was generated using DEM, rain data collected from Birjand Meteorological Department, and soil permeability data collected from Jihad Agricultural Office were considered as input data.Ranges and classes are listed in Table 2. The aquifer media in the DRASTIC model shows the intrinsic hydrogeology of the subsurface.Subsurface hydrgeologic processes such as groundwater recharge, contaminant displacement, etc., are influenced by the characteristics of the aquifer media(Remesan and Panda, 2008). The wells data collected from the Regional water Department of southern Khorasan Province to prepare the aquifer map. The Birjand aquiferwas divided into two major geological formations. The part of the aquifer that contains sand and gravel coarse-grained deposits is assigned a higher rating of 9.Soil textures determine the potential for groundwater vulnerability and 
control the movement of pollutants from the surface to the water table by soil grain size(Remesan and Panda, 2008). The permeability parameter was used to rating different soil types (Table 1).Four types of soil were identified in the Birjand aquifer. The highest rating was assigned to highly permeable soil (gravel) and the lowest value was assigned to soil with less permeability (loam). (Karthikeyan and Lakshmanan, 2012). The topography of an area refers to the characteristics of the surface and slope. Areas with lower slopes are more prone to pollution. The lower the slope, the less runoff and the greater the infiltration (Al-Adamat et al., 2003). A slope map was prepared using a digital elevation model (DEM) with spatial resolution of 30 meters and was divided into three classes: 0-2, 2-6 and 6-12 percentage. In this site, nearly flat areas were allocated a high rating value of 10 , and the steepest slopes receiving the lowest rating of 5. The vadose area includes the unsaturated area between the topsoil (soil cover) and the water table. The permeability of the materials of this layer has a great impact on the transmission of contamination. According to Aller and Robert (1985), and based on the geological description of the research area, the vadose zone was divided into three classes. The ability of the aquifer to transfer water that is constantly flowing in it is called hydraulic conductivity (Saha and Alam, 2014). Aquifers with the highest levels of hydraulic conductivity are most at risk of contamination(Tomer et al., 2019).The value of hydraulic conductivity ranged between 4.32 and $43.2 \mathrm{~m} /$ day, for the study area.

A final vulnerability map was created in ArcGIS 10.6 after determining the weight and rating of each parameter. The DRASTIC vulnerability index was calculated by combining the effects of each of the seven layers which calculated using ArcGIS 10.6 and according to Eq. 1.The value of this index is between 79 and 146 and it was classified into four categories of low to very high vulnerability to groundwater pollution(Fig. 6A). A quantile classification method was used to classify vulnerability categories in the final map. The high vulnerability was driven chiefly by the shallow water level, high hydraulic conductivity, and porous Vadose area, or the effect of all three together.

In most studies, the conventional DRASTIC model has been used to investigate the vulnerability of groundwater to pollution. The DRASTIC model considers the transfer of pollutants to groundwater through the unsaturated zone but does not take into account the pollution caused by anthropogenic effects and this can result in unrealistically low DRASTIC index (Shirazi et al., 2013). The anthropogenic activities are found in different forms in different study areas. For example, in this study, anthropogenic effects have been considered in the form of land use, such as agricultural areas or residential areas, etc. For this purpose, the land use parameter was added to the original DRASTIC model. The rating and weight of the anthropogenic impact map were determined according to the land use class contracts (Al-Adamat et al., 2003; Maqsoom et al., 2020) to produce a vulnerability map of MDRASTIC(Fig.6B). The parameters that had the least impact on groundwater pollution include soil media, aquifer media, and topography while water depth table, land use, and hydraulic conductivity had the greatest impact among the parameters. The MDRASTIC map is classified into four vulnerability categories (very high, high, medium and low). Most of the study area was located in a highly vulnerable area. High vulnerability is observed in areas around gardens, agricultural areas and residential areas. To provide a better and more realistic method for classifying groundwater vulnerability, the MDRASTIC model parameters were modified using a analytic hierarchical process (AHP) (Sener and Davraz, 2012). Using the parameters of the MDRASTIC model, a comparison matrix was 
generatedand new weights and ratings were calculated for each parameter. Super decision software was used to prepare the weight of the parameters by Analytic Hierarchy Process. The results of the MDrastic-AHP Vulnerability Map showed that the western and southwestern regions are more prone to contamination. Low pollution potential areas in southern and eastern part which consists mostly of grasslands and forests was determined. To ensure better decisions and results, the weights of all eight parameters of the MDRASTIC vulnerability index were also modified with the help of weights obtained from the FAHP (Table 4). After that, each of the parameters was evaluated and paired comparisons by themselves and their rates were corrected. At each stage, after obtaining new weights, the compatibility ratios of the comparison matrices were obtained using Gogus andBoucher methods (1997). Using GIS tool, the final vulnerability map was prepared. After preparing the vulnerability results, it was found that the pollution potential in the southwestern regions is very high.There is uncertainty and ambiguity in the DRASTIC model because the classification of each parameter is graded based on the opinions of experts.To reduce this problem, the results of DRASTIC models zoning maps are confirmed by comparing the sensitive areas of the Birjand aquifer with the available nitrate concentration. Then, each parameter is analyzed separately for sensitivity.

\section{Conclusion}

In this study, using the experimental model of DRASTIC in GIS environment, the sensitivity of water to pollution in the aquifer of Birjand Plain was evaluated. In addition, land use patterns were used to create a better model called MDRASTIC or DRASTIC-LU. Due to the importance of weight values of DRASTIC parameters, AHP and FAHP methods were used to determine the weight values parameters. After calculating the vulnerability index, a vulnerability map of each method was prepared. To better understand and also show the vulnerability of the region, the final index obtained from each method was classified into four different classes. The results of the sensitivity analysis show that depth to the water table and land use have the most impact on vulnerability assessment in the Birjand aquifer, while net recharge and topography are the parameters that have the least impact in the study area. In order to verify the built methods, the relationship between the vulnerability index and the values of nitrate concentration obtained from 22 groundwater samples has been investigated. To determine the correlation coefficient, simple linear regression method was used in Excel and Pearson, Spearman methods were used in SPSS 26. The results obtained from the correlation coefficient show that the MDRASTIC-FAHP method has the highest

\section{Declarations}

Ethics approval and consent to participate Not applicable

Consent for publication

Not applicable

Availability of data and materials

Due to the nature of this research, participants of this study did not agree for their data to be shared publicly, so supporting data is not available. 
Competing interests

The authors declare that they have no competing interests

Funding

No funding was received for this work

Author contributions

An author must take responsibility for at least one component of the work, should be able to identify who is responsible for each other component, and should ideally be confident in their co-authors' ability and integrity.

\begin{tabular}{c|c}
\hline Component of the research & Author's name \\
\hline Conceptualization & Mohammad Reza Goodarzi - Amirreza R. Niknam - Hamid Reza \\
Pourghasemi
\end{tabular}

\section{References}

Abdelmadjid B, Omar S (2013) Assessment of groundwater pollution by nitrate using intrinsic vulnerability methods: A case study of the Nil valley groundwater (Jijel, North-East Algeria), Afr. J. Environ. Sci. Technol. 7 (10): 949-960.

Abdullah TO, Ali SS, Al-Ansari NA, Knutsson S (2018) Possibility of Groundwater Pollution in Halabja Saidsadiq Hydrogeological Basin, Iraq Using Modified DRASTIC Model Based on AHP and Tritium Isotopes. Geosci. 8(7): 236. 
Aller L, Robert S (1985) DRASTIC: A Standardized System for Evaluating Ground Water Pollution Potential Using Hydrogeologic Settings, Kerr Environmental Research Laboratory, Office of Research and Development, U.S. Environmental Protection Agency.

Al-Adamat RAN, Foster IDL, Baban SMJ (2003) Groundwater vulnerability and risk mapping for the Basaltic aquifer of the Azraq basin of Jordan using GIS, Remote sensing and DRASTIC. Appl Geogr. 23(4): 303324.

Aryafar A, Khosravi V, Karami S (2020) Groundwater quality assessment of Birjand plain aquifer using kriging estimation and sequential Gaussian simulation methods. Environ. Earth Sci. 79(10): 210.

Asgari Moghaddam A, Nadiri A, Pakniya V (2016) Vulnerability Assessment of Bostan Abad Plain Qquifer by DRASTIC and SINTACS Models. Hydrogeomorph. 3(8): 21-52.

Awawdeh MM, Jaradat RA (2010) Evaluation of aquifers vulnerability to contamination in the Yarmouk River basin, Jordan, based on DRASTIC method. Arab. J. Geosci. 3(3): 273-282.

Baghapour MA, Talebbeydokhti N, Tabatabaei SH, Fadaei Nobandegani A (2014) Assessment of Groundwater Nitrate Pollution and Determination of Groundwater Protection Zones Using Drastic And Composite Drastic (cd) Models: The Case of Shiraz Unconfined Aquifer. J. Health Sci. Surveill. Syst. 2.-(2)

Baghapour MA, Fadaei Nobandegani A, Talebbeydokhti N, Bagherzadeh S, Nadiri AA, Gharekhani M, Chitsazan N (2016) Optimization of DRASTIC method by artificial neural network, nitrate vulnerability index, and composite DRASTIC models to assess groundwater vulnerability for unconfined aquifer of Shiraz Plain, Iran. J. Environ. Health Sci. Eng. 14(1): 13.

Bai L, Wang Y, Meng F (2012) Application of DRASTIC and extension theory in the groundwater vulnerability evaluation. Water Environ. J. 26(3): 381-391.

Chang D.-Y (1996) Applications of theextent analysis method on fuzzy AHP. Eur. J. Oper. Res. 95(3): 649-655.

Chok NS (2010) Pearson's Versus Spearman's and Kendall's Correlation Coefficients for Continuous Data. Master's Thesis.

Daly D, Drew D (1999) Irish methodologies for karst aquifer protection. Hydrogeol Eng Geol Sinkholes Karst Balkema, Rotterdam. 272_267.

Doerfliger N, Zwahlen F (1997) EPIK: A new method for outlining of protection areas in karstic environment. In International Symposium and Field Seminar on "Karst Waters and Environmental Impacts. Gunay, G., Jonshon, A.I., Eds.; IAEA: Antalya, Turkey; Balkema, Rotterdam, 117-123

Edet A (2014) An aquifer vulnerability assessment of the Benin Formation aquifer, Calabar, southeastern Nigeria, using DRASTIC and GIS approach. Environ. Earth Sci. 71(4): 1747-1765.

Eftekhari M, Akbari M, Ghezelsofloo AA (2019) Qualitative Vulnerability Assessment of Birjand Plain Aquifer Using SINTACS Method. J. Nat. Environ. 72(3). (In Persian)

Foster S, Hirata R, Gomes D, Paris M, D'Elia M (2002) Groundwater quality protection - a guide for water utilities, municipal authorities and environment agencies (also in Spanish \& Portuguese).

Ghosh A, Tiwari AK, Das S (2015) A GIS based DRASTIC model for assessing groundwater vulnerability of Katri Watershed, Dhanbad, India. Model. Earth Syst. Environ. 1 (3): 11. 
Gogu RC, Dassargues A (2000) Sensitivity analysis for the EPIK method of vulnerability assessment in a small karstic aquifer, southern Belgium. Hydrogeol. J. 8(3): 337-345.

Gogus O, Boucher TO (1997) Aconsistency test for rational weights in multi-criterion decision analysis with fuzzy pairwise comparisons. Fuzzy Set. Syst. 86(2): 129-138.

Guo Q, Wang Y, Gao X, Ma T (2006) A new model (DRARCH) for assessing groundwater vulnerability to arsenic contamination at basin scale: a case study in Taiyuan basin, northern China. Environ. Geo. 52(5): 923-932.

Hussain Y, Ullah SF, Aslam AQ, Hussain MB, Akhter G, Martinez-Carvajal HE, Satgé F, Ashraf A, Iqbal, B, Cárdenas-Soto M (2017) Vulnerability assessment of an agro-stressed aquifer using a source-pathwayreceptor model in GIS. Model Earth Syst Environ. 3(2): 595-604.

Jesiya NP, Gopinath G (2019) A Customized FuzzyAHP - GIS based DRASTIC-L model for intrinsic groundwater vulnerability assessment of urban and peri urban phreatic aquifer clusters. Groundw. Sustain. Dev. 8: 654666.

Kahraman C, Cebeci U, Ulukan Z (2003) Multi-criteria supplier selection using fuzzy AHP. Logist. Inf. Manag. 16(6): 382-394.

Karami Shahmaleki N, Behbahani SMR, Massah Bavani A, Khodaei K (2013) Comparison between LogisticRegression, Modified DRASTIC and AHP-DRASTIC Methods in Groundwater Vulnerability Assessment. J. Environ. Stud. 38(4): 79-92.

Karthikeyan B, Lakshmanan E (2012) Impact of Tanning Industries on Groundwater Quality near a Metropolitan City in India. Water Resour. Manag. 26: 1747-1761.

Kim YJ, Hamm S.-Y (1999) Assessment of the potential for groundwater contamination using the DRASTIC/EGIS technique, Cheongju area, South Korea. Hydrogeol. J. 7(2): 227-235.

Kumar A, Pramod Krishna A (2019) Groundwater vulnerability and contamination risk assessment using GIS-based modified DRASTIC-LU model in hard rock aquifer system in India. Geocarto Int. 35(11): 1149-1178.

Kumar S, Venkatesh AS, Singh R, Udayabhanu G, Saha D (2018) Geochemical signatures and isotopic systematics constraining dynamics of fluoride contamination in groundwater across Jamui district, Indo-Gangetic alluvial plains, India. Chemosphere. 205: 493-505.

Laerd Statistics: Lund Research Ltd. 2018. [accessed 2018 July 3]. https://statistics.laerd.com/-spsstutorials/spearmans-rank-order-correlation-using-spss-statistics.php.

Lakusic S (2019) Groundwater vulnerability mapping using modified DRASTIC ANP. J. Croatian Assoc.Civ. Eng. 71(4): 283-296.

Lee S (2003) Evaluation of waste disposal site using the DRASTIC system in Southern Korea. Environ. Geol. 44(6): 654-664.

Mahmoudzadeh E, Rezaian S, Ahmadi A (2013) Assessment of Meymeh Plain Aquifer Vulnerability in Esfahan Using Comparative Method AVI,GODS,DRASTIC. J. Environ. Stud. 39(2): 45-60.

Maqsoom A, Aslam B, Khalil U, Ghorbanzadeh O, Ashraf H, Faisal Tufail R, Farooq D, Blaschke T (2020) A GISbased DRASTIC Model and an Adjusted DRASTIC Model (DRASTICA) for Groundwater Susceptibility Assessment along the China-Pakistan Economic Corridor (CPEC) Route. Int. J. Geo-Inform. 9.(5) 
Martínez-Bastida JJ, Arauzo M, Valladolid M (2010) Intrinsic and specific vulnerability of groundwater in central Spain: the risk of nitrate pollution. Hydrogeol. J., 18(3): 681-698.

Napolitano P, Fabbri A (1996) Single-parameter sensitivity analysis for aquifer vulnerability assessment using DRASTIC and SINTACS. IAHS-AISH Publication, 235: 559-566.

Natraj VM, Katyal D (2014) Study of fertilizer effect on soil status in and around Loni, Maharashtra, India. In: Proceedings of 3rd World Conference on Applied Sci. Engg. Tech. 188-192 (Kathmandu, Nepal).

Neshat A, Pradhan B (2017) Evaluation of groundwater vulnerability to pollution using DRASTIC framework and GIS. Arab. J. Geosci. 10(22): 501.

Noori R, Ghahremanzadeh H, Klove B, Adamowski JF, Baghvand A (2019) Modified-DRASTIC, modifiedSINTACS and SI methods for groundwater vulnerability assessment in the southern Tehran aquifer. J Environ Sci Health A Tox Hazard Subst Environ. Eng. 54(1): 89-100.

Pacheco FAL, Pires LMGR, Santos RMB, Sanches Fernandes LF (2015) Factor weighting in DRASTIC modeling. Sci. Total Environ. 505: 474-486.

Panagopoulos GP, Antonakos AK, Lambrakis NJ (2006) Optimization of the DRASTIC method for groundwater vulnerability assessment via the use of simple statistical methods and GIS. Hydrogeol. J. 14(6): 894-911.

Pathak DR, Hiratsuka A, Awata I, Chen L (2009) Groundwater vulnerability assessment in shallow aquifer of Kathmandu Valley using GIS-based DRASTIC model. Environ. Geol. 57(7): 1569-1578.

Piscopo.G (2001) Groundwater vulnerability map explanatory notes. Castlereagh Catchment, NSW. Department of Land and Water Conservation, Australia.

Saaty T (1980) Multicriteria decision making : the analytic hierarchy process ; planning, priority setting, resource allocation. New York McGraw-Hill 1988.

Saha D, Alam F (2014) Groundwater vulnerability assessment using DRASTIC and Pesticide DRASTIC models in intense agriculture area of the Gangetic plains, India. Environ. Monit. Assess. 186.

Sener E, Davraz A (2012) Assessment of groundwater vulnerability based on a modified DRASTIC model, GIS and an analytic hierarchy process (AHP) method: The case of Egirdir Lake basin (Isparta, Turkey). Hydrogeol. J., 21.

Şener E, Şener Ş, (2015) Evaluation of groundwater vulnerability to pollution using fuzzy analytic hierarchy process method. Environ. Earth Sci. 73(12): 8405-8424.

Sener E, Şener Ş, Davraz A (2009) Assessment of aquifer vulnerability based on GIS and DRASTIC methods: A case study of the Senirkent-Uluborlu Basin (Isparta, Turkey). Hydrogeol. J. 17: 2023-2035.

Shirazi SM, Imran HM, Akib S, Yusop Z, Harun ZB (2013) Groundwater vulnerability assessment in the Melaka State of Malaysia using DRASTIC and GIS techniques. Environ. Earth Sci. 70(5): 2293-2304.

Simsek C, Kincal C, Gunduz O (2006) A solid waste disposal site selection procedure based on groundwater vulnerability mapping. Environ. Geol. 49(4): 620-633.

Sinha MK, Verma MK, Ahmad I, Baier K, Jha R, Azzam R (2016) Assessment of groundwater vulnerability using modified DRASTIC model in Kharun Basin, Chhattisgarh, India. Arabian J. Geosci. 9(2): 98. 
Singha S, Pasupuleti S, Singha S, Villuri VGK (2017) An integrated approach for evaluation of groundwater quality in Korba district, Chhattisgarh using Geomatic techniques. J. Environ. Bio. 38(5): 865-872.

Stempvoort DV, Ewert L, Wassenaar L (1993) Aquifer Vulnerability Index: A Gis - Compatible Method for Groundwater Vulnerability Mapping. Can. Water Resour. J. 18(1): 25-37.

Tiwari AK, Singh PK, De Maio M (2016) Evaluation of aquifer vulnerability in a coal mining of India by using GIS-based DRASTIC model. Arab. J. Geosci. 9(6): 438.

Tomer T, Katyal D, Joshi V (2019) Sensitivity analysis of groundwater vulnerability using DRASTIC method: A case study of National Capital Territory, Delhi, India. Groundw. Sustain. Dev. 9.

Tseng M, Lin Y, Chiu A, Chen C (2008) Fuzzy AHP approach to TQM strategy evaluation. IEMS 7(1):34-43.

Umar R, Ahmed I, Alam F (2009) Mapping groundwater vulnerable zones using modified DRASTIC approach of an alluvial aquifer in parts of central Ganga plain, Western Uttar Pradesh. J. Geolog. Soci. In. 73(2): 193201.

USEPA (1985) DRASTIC: a standard system for evaluating groundwater potential using hydrogeological settings. WA/EPA Series 1 ,985US EPA, Washington, DC, 163,pp.

van Laarhoven PJM, Pedrycz W (1983) A fuzzy extension of Saaty's priority theory. Fuzzy Set. Syst. 11(1): 229241.

Vrba J, Zaporožec A (1994) Guidebookon mapping groundwater vulnerability, H. Heise, Hannover.

Wang Y, Merkel BJ, Li Y, Ye H, Fu S, Ihm D (2007) Vulnerability of groundwater in Quaternary aquifers to organic contaminants: a case study in Wuhan City, China. Environ. Geo. 53: 479. 
Figures
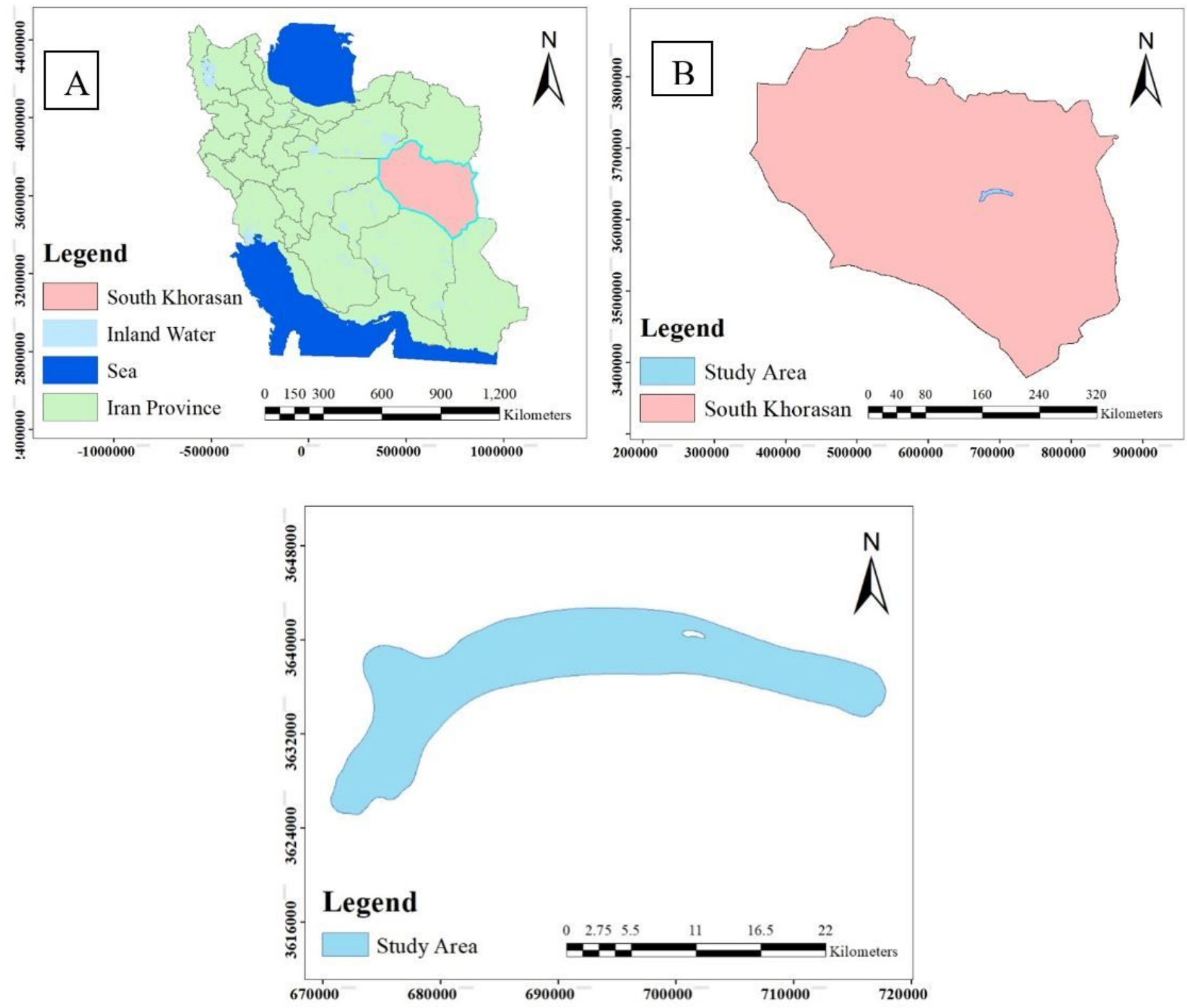

\section{Figure 1}

Location of the study area in Iran (A) and south Khorasan (B). Note: The designations employed and the presentation of the material on this map do not imply the expression of any opinion whatsoever on the part of Research Square concerning the legal status of any country, territory, city or area or of its authorities, or concerning the delimitation of its frontiers or boundaries. This map has been provided by the authors. 

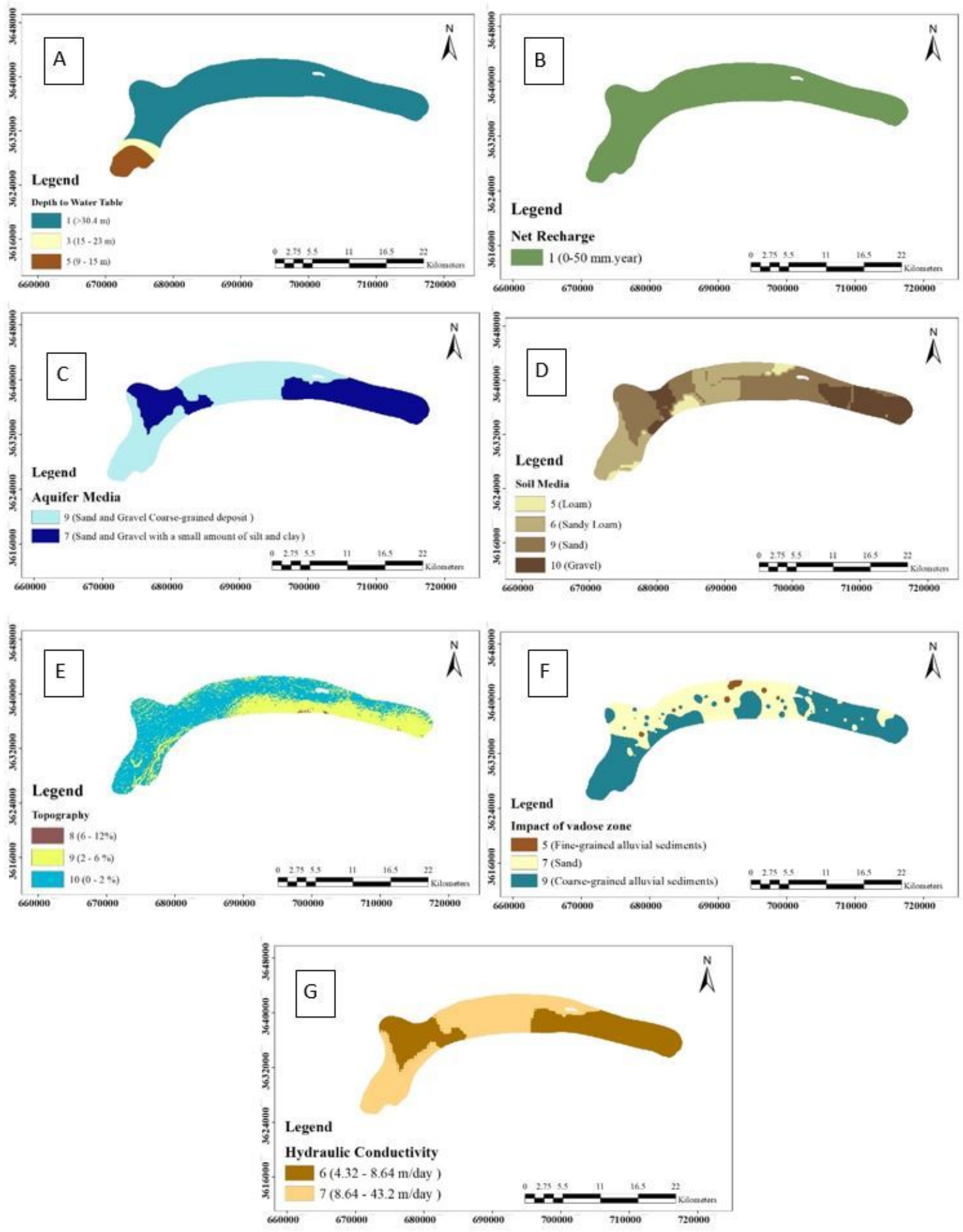

Figure 2

A) Water Depth; B) Net Recharge; C) Aquifer Media; D) Soil Media; E) Topography; F) Impact of vadose zone; G) Hydraulic conductivity 


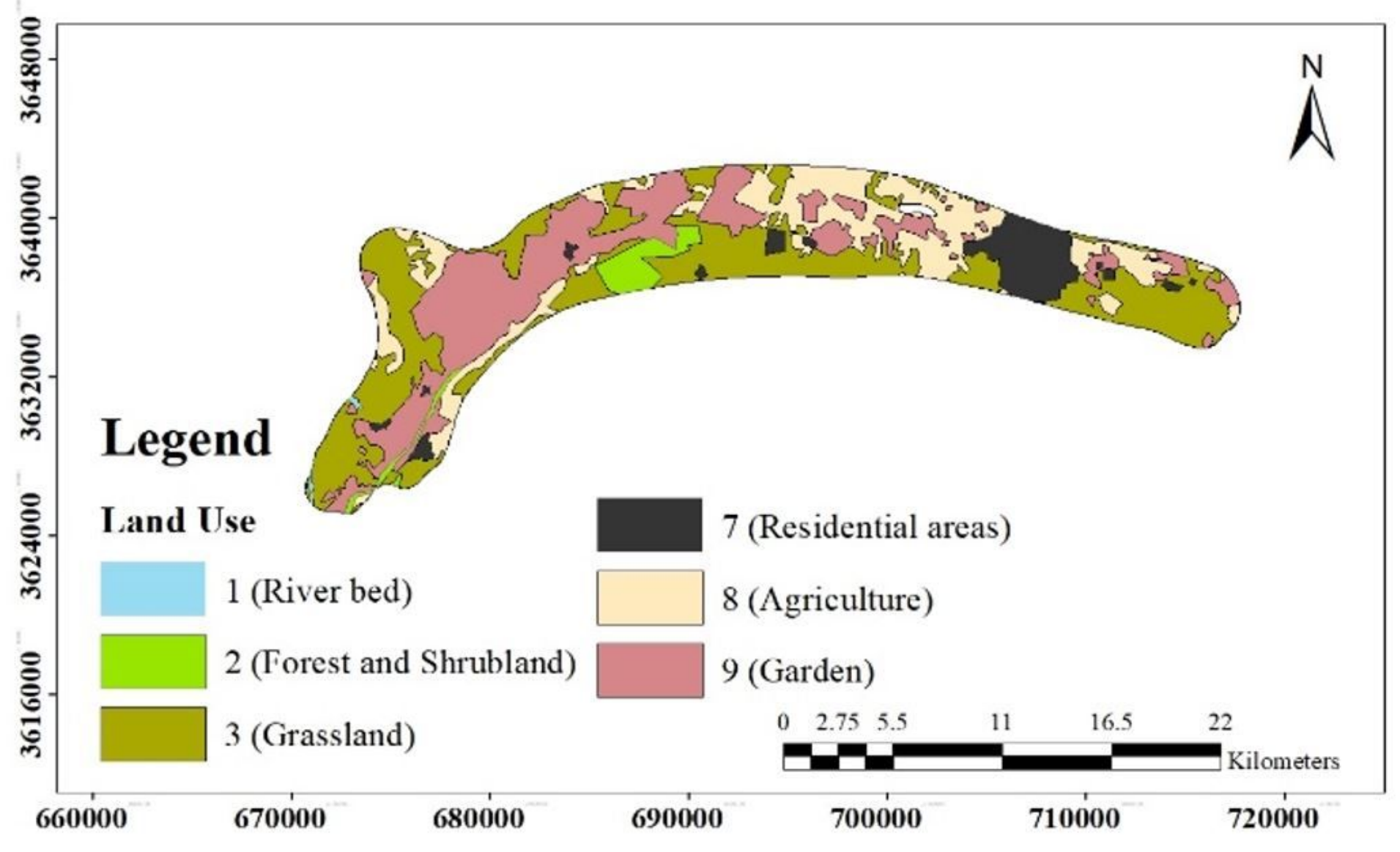

Figure 3

Land use map of the Birjand Plain 


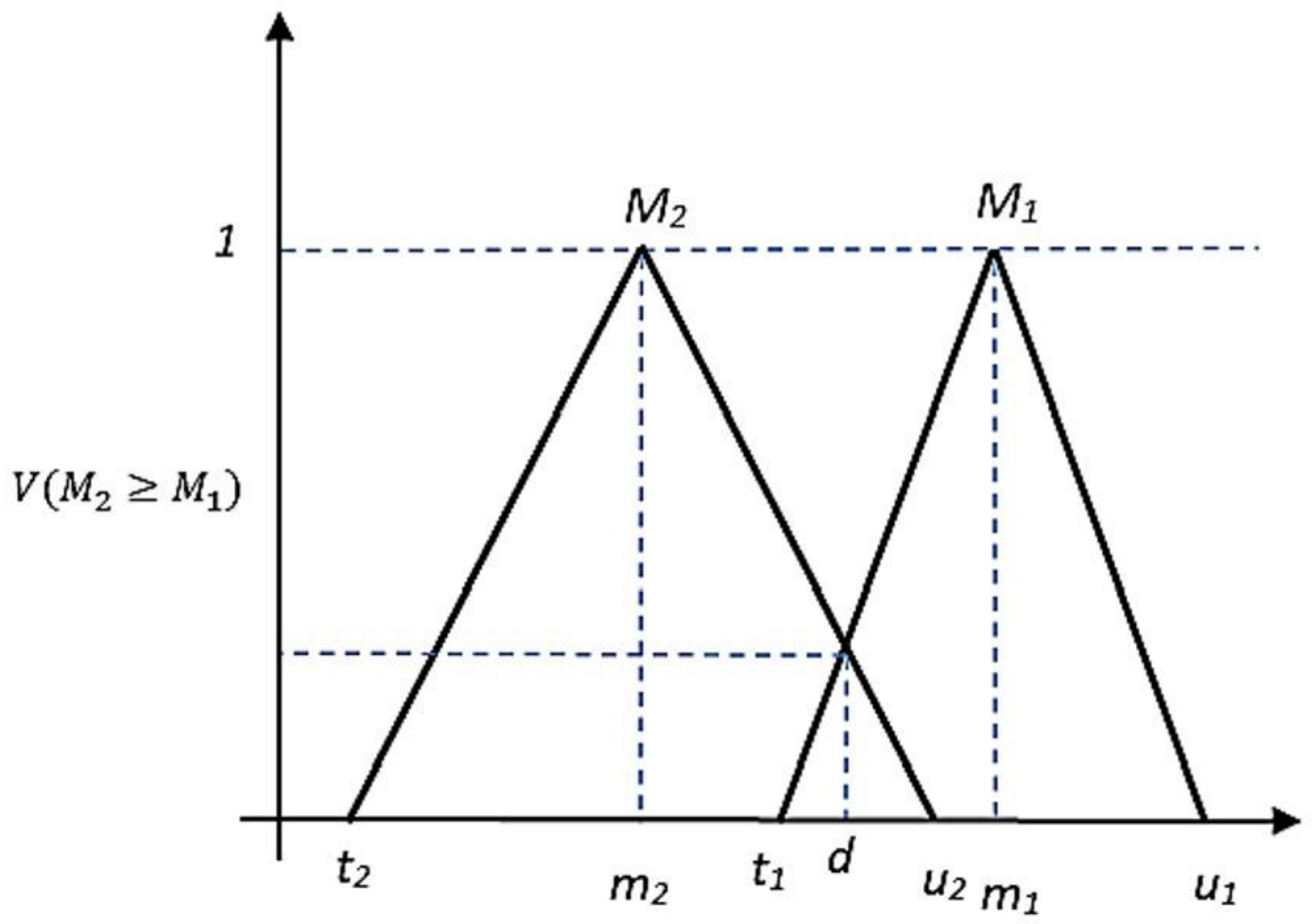

Figure 4

The intersection between M1 and M2 (Şener and Şener 2015)

Inconsistency: 0.02347

\begin{tabular}{|l|l|l|}
\hline A & & 0.15958 \\
\hline C & & 0.09548 \\
\hline D & & 0.26561 \\
\hline I & & 0.12159 \\
\hline LU & R & 0.20334 \\
\hline S & & 0.03735 \\
\hline T & & 0.07357 \\
\hline
\end{tabular}

Figure 5

Results of estimating the weights of MDRASTIC parameters in super decision 

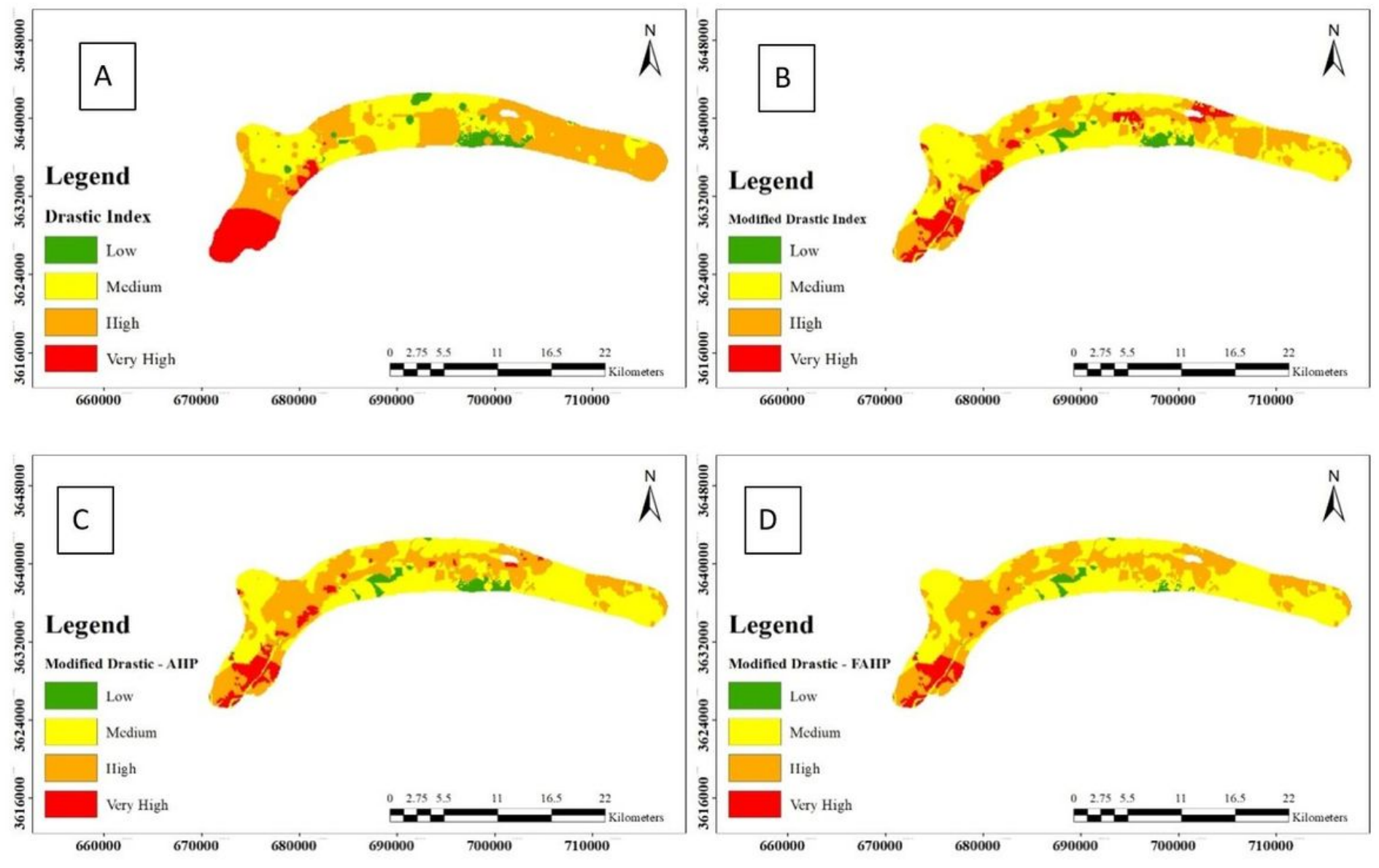

Figure 6

Groundwater vulnerability maps A) DRASTIC; B) MDRASTIC; C) MDRASTIC-AHP; D) MDRASTIC-FAHP 


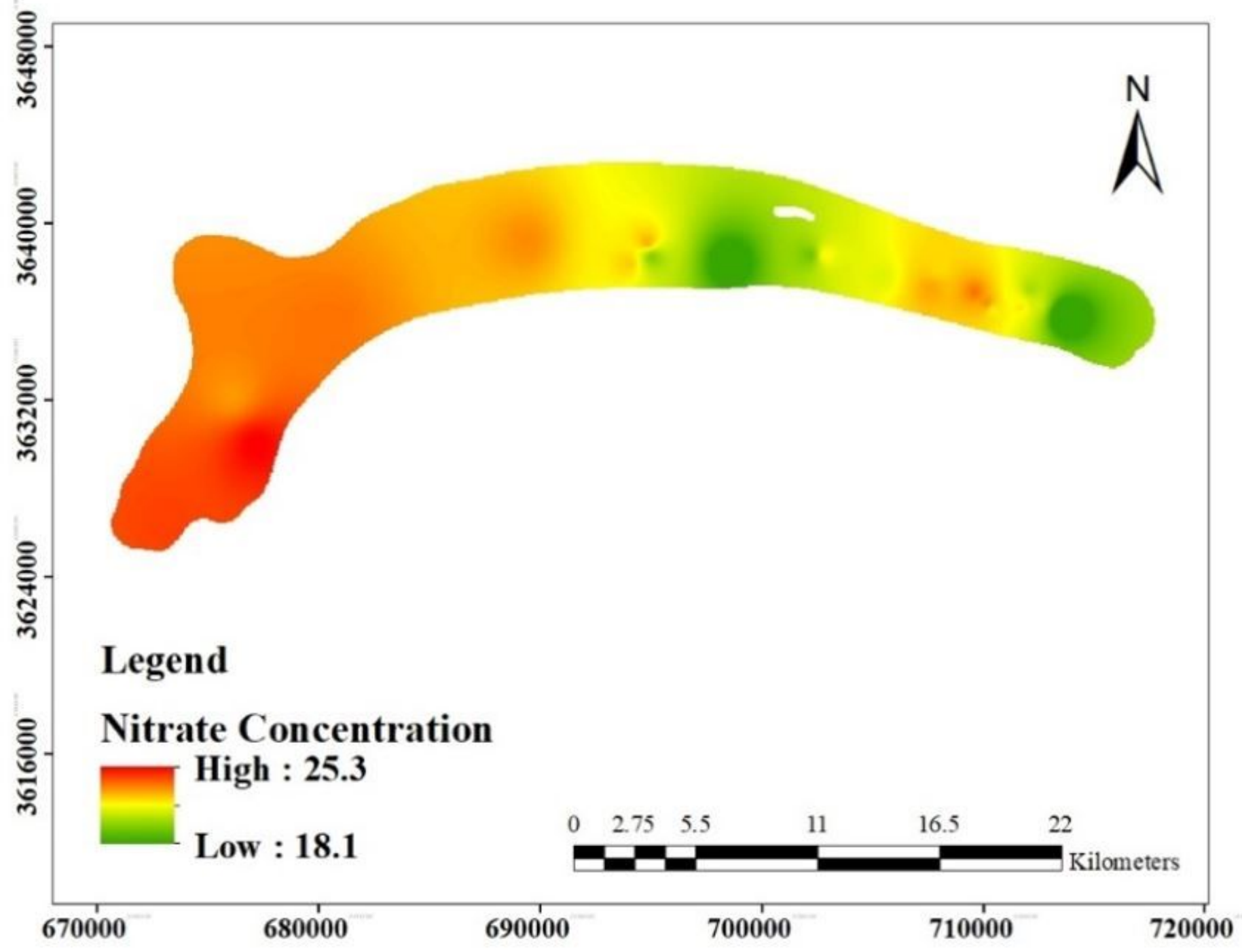

Figure 7

Nitrate concentration in groundwater of Birjand plain aquifer 

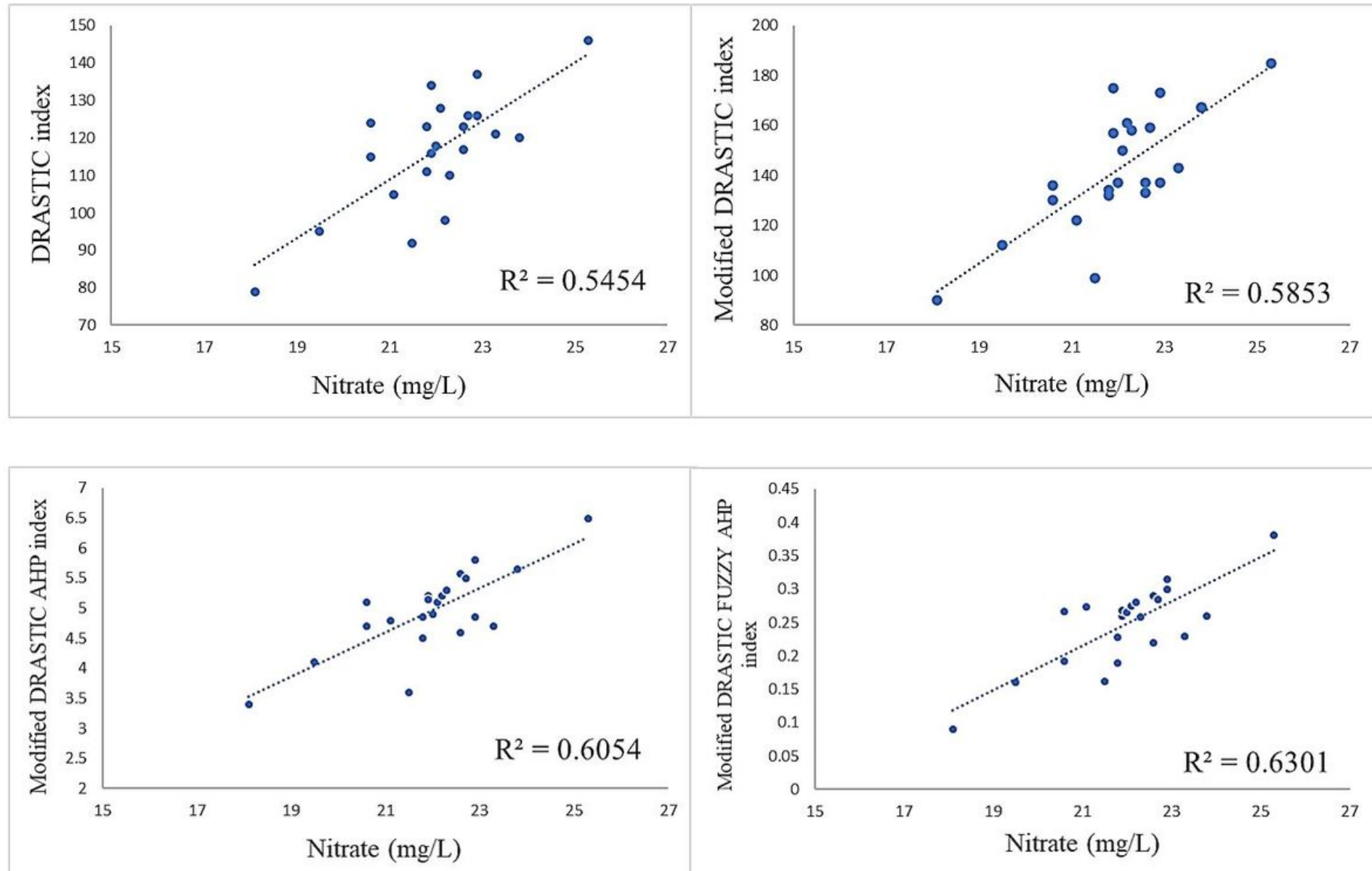

Figure 8

Relationship between aquifer vulnerability maps obtained from each method and nitrate concentration: A) DRASTIC, B) MDRASTIC, C) MDRASTIC-AHP D) MDRASTIC-FAHP

\section{Supplementary Files}

This is a list of supplementary files associated with this preprint. Click to download.

- GraphicalAbstractOriginal1.docx

- HighlightsOriginal.docx 